Original Research Paper

\title{
Characteristics of Cut Head Hair: An Evidence in Criminal Investigations
}

\author{
${ }^{1}$ Pol. Maj. Satina Polyiam, ${ }^{2}$ Pol. Lt. Sasithorn Boonmapa, ${ }^{3}$ Wuttichai Phae-Ngam and ${ }^{4}$ Pichet Limsuwan \\ ${ }^{1}$ Chemistry Physics Sub-Division, Central Scientific Crime Detection Division Royal Thai Police, Bangkok 10330, Thailand \\ ${ }^{2}$ Chemistry Physics Sub-Division, Scientific Crime Detection Center 5, Royal Thai Police Lampang 52000, Thailand \\ ${ }^{3}$ Physics Program, Faculty of Science and Technology, Phranakhon Rajabhat University, Bangkok 10220, Thailand \\ ${ }^{4}$ Department of Physics, Faculty of Science, King Mongkut's University of Technology Thonburi Bangkok 10140, Thailand
}

\author{
Article history \\ Received: 04-06-2021 \\ Revised: 08-09-2021 \\ Accepted: 09-09-2021 \\ Corresponding Author: \\ Pichet Limsuwan \\ Department of Physics, Faculty \\ of Science, King Mongkut's \\ University of Technology \\ Thonburi Bangkok 10140, \\ Thailand \\ Email: pichetlaser@gmail.com
}

\begin{abstract}
One hot news occurred in Thailand one year ago was a 3-year-old girl was murdered and only a number of hair strands were found near her body and likely cut by a knife. Later some cut hairs were found at the cloth of the suspect. In this study, the authors would like to match the hairs found at the crime scene with the hair found at the suspect's ware. However, the real hairs obtained from such case could not be used for this study. Therefore, the head-hair samples were cut from one author of this study. Then, the structural properties including the size, cutting angle and surface morphology of the cut hairs were investigated using scanning electron microscopy. The results on the cutting of two hair strands and five hair strands at the same time showed that the cut hairs could be verified that they came from the same person. Furthermore, if a number of cut hairs were found at the crime scene and some hairs were found at the suspect's ware, such as at the cloth or in the car, by the method used in this study it can also verify that all hairs were cut at the same time and came from the same person.
\end{abstract}

Keywords: Forensic Analysis of Hair, Hair Evidence, Scanning Electron Microscopy (SEM)

\section{Introduction}

Hair samples are one of the most important evidence in the forensic analysis of crime scenes. Hair analysis has been widely used in the fields of forensic toxicology and environmental toxicology. In forensic toxicology, the first research article was published in 1979 regarding the detection of heroin from hair (Baumgartner et al., 1979). Then, the hair analysis for the detection of many drugs has been extensively studied including cocaine (Baumgartner et al., 1982; Graham et al., 1989; Marques et al., 1993; Kelly et al., 2000) nicotine (Ishiyama et al., 1983), morphine (Marigo M. et al., 1986; Offidani et al.,1993) opiates, (Püschel et al., 1983; Kintz and Manging, 1993) and amphetamines (Ishiyama et al., 1983; Suzuki et al., 1984; Nagai et al., 1988; Miki et al., 1997; Kelly et al., 2000). In environmental toxicology, hair analysis is used for the detection of the presence of heavy metals (toxic substances) deleterious to health after exposing to air, dust, sediment, soil and water (Dorea et al., 1989; Stewart-Pinkham et al., 1989).
For more details on the forensic examination of hair, the following reviewed books and research articles are recommending for further reading. An early review on forensic examination of hair is published in the book edited by Robertson (1999) and a complete review on chemical and physical behavior of human hair is published in the book by Robbins (2012). Recently, a review on forensic toxicological analysis of hair is published in the paper by Usman et al. (2019).

The method in forensic toxicological analysis of hair as firstly reported by Baumgartner et al. (1979); Baumgartner et al. (1979) was radioimmunoassay. At present, many new analytical methods used for extraction of drugs in hair have been developed and reported in literatures, such as MALDI-MSI: Matrix-assisted laser desorption/ionization mass spectrometric imaging (Porta et al., 2011), DART-MS: Direct analysis in real time mass spectrometry (Duvivier et al., 2014), MALDI-ToF-MSI: Matrix-assisted laser desorption/ionization time-of-flight mass spectrometry imaging (Nakanishi et al., 2014), ToF-SIMS: Time-of-flight 
secondary ion mass spectrometry (Flinders et al., 2015) and LC-MS/MS: Liquid chromatography tandem mass spectrometry (Kuwayama et al., 2016). A complete list of methods developed from 1982 to 2016 has been collected and published by Allibe et al. (2017). In addition, the methods for extraction from the hair sample for analysis of drugs using chromatography-base methods have been collected and published by Khajuria et al. (2018).

In the field of forensic analysis of hair evidence in criminal investigations, the study of morphological, physical and mechanical properties of hair are generally required. For physical property, such as structural characteristics, the human hair is taken from crime scene and taken from a suspect were investigated to confirm matching of their structural characteristics. The structural characteristics of human hairs in the forensic laboratory have traditionally been conducted by many methods, such as optical microscopy, Scanning Electron Microscopy (SEM), Atomic Force Microscopy (AFM) and optical coherence tomography (Thozhur et al., 2006; Velasco et al., 2009; Bhushan, 2008). These techniques have been used in criminal investigation to match the hair found at a crime scene with the hair of a suspect. In the 1990 s, DNA analysis was introduced as a new technique into forensic investigations. However, for DNA analysis of human hair sample, the hairs must contain a root portion.

One hot news occurred in Thailand about one year ago was a 3-year-old girl disappeared from her home in Dong Luang district, Mukdahan province, Thailand on May 11, 2020. On May 14, 2020, her murdered body was found in the forest, about $2 \mathrm{~km}$ from her home. The significant evidence that the polices found and collected near her body were hair samples. The 36 hair strands were found and likely cut by a knife. A month later, 2 hair strands were found and collected from the cloth of the suspect by the polices.

Two authors of this research article, Pol. Maj Satina Polyiam and Pol. Lt. Sasithorn Boonapa, who work with The Crime Detection Division, Royal Thai Police, Thailand has been appointed as researchers for investigation of 36 cut hair strands and try to match with 2 hair strands found in the suspect's cloth. The structural properties including diameter, surface morphology, angular-cut appearance and cutting angle of both groups of hair samples were characterized and the results have been submitted to The Crime Detection Division for further processing of the crime investigation. Even though the results obtained from the real case as mentioned above are secret and cannot be disclosed to the public at this moment, some scientific techniques used in this case may be useful for further study in forensic science.

To the best of our knowledge, so far, the forensic study on the cut hairs has not yet been reported in the literatures. Therefore, in this study, we carried out similar study to that real case by cutting the head hair of one researcher in this project. Then, the structural property was characterized using scanning electron microscopy (JEOL, JSM-IT300L). The size, cutting angle and surface morphology were presented and discussed.

\section{Materials and Methods}

\section{Equipment}

A pocket knife (Xtive Pro, People Republic of China) was used for cutting the hairs. The weight of the knife was $300 \mathrm{~g}$ and the blade was made of stainless steel. The dimensions of the (Width, W, $\times$ Length, $\mathrm{L}, \times$ thickness, $\mathrm{H})$ of the handle was $2.5 \times 11.5 \times 1.5 \mathrm{~cm}$. The size (Width, W, $\times$ Length, L) of the blade was $2.5 \times 9 \mathrm{~cm}$. The thickness of the unsharp and sharp blades were 0.25 and $0.10 \mathrm{~cm}$, respectively.

\section{Sample Preparation}

The head-hair samples were obtained from an author of this article, Pol. Maj Satina Polyiam, a female of age 34 years old and worked with The Central Scientific Crime Detection Division, Royal Thai Police, Bangkok, Thailand. The hair cutting processes were carried out as follows.

\section{Cutting of Two Hairs at the Same Time}

The experimental setup for the cutting of two hairs at the same time is shown in Fig. 1. The tip of two hairs were held and separated out of the hairs on the head. They were pulled in order to make them parallel and close in touch each other From Fig. 1. The right hand of the worker held the tip of the hairs tightly. While the left hand held a knife and put it perpendicular to the hairs at a distance of about $2 \mathrm{~cm}$ from the tip of the hairs. Then, pressing the sharp blade on the hairs and both hairs were cut in one pressing force. Please note that the worker in Fig. 1 has a left-handed skill.

\section{Cutting of Five Hairs at the Same Time}

The experimental setup for the cutting of five hairs at the time is the same as of two hairs cutting. The tip of five hairs was pulled and arranged them in horizontal plane. The sharp blade of the knife was held the vertical direction, perpendicular to the hairs and parallel to the horizontal plane at a position of about $2 \mathrm{~cm}$ from the tip of the hairs. Then, pressing the sharp blade on the hairs and all five hairs were cut at the same time.

\section{Determination of Cutting Angle}

Figure 2(a) shows a hair by assuming it has a cylindrical shape. For ideal case, if the hair is cut along the cutting direction, then the cutting plane with roughly elliptical shape is observed as shown in Fig. 2(b). In the real cutting of the hairs, the cutting plane is not one smooth cutting plane. At the beginning, due to the elasticity of the hair, the blade cannot cut through the hair but it slipped off the initial cutting direction as shown in 
Fig. 3(a). The blade slipped to some depth and make a slipped off the plane, then it suddenly cut through the hair with a cutting plane making an angle $(\theta)$ with respect to initial cutting direction as shown in Fig. 3(b). The cutting angle, $\theta$ is determined by Eq. (1):

$$
\theta=\cos ^{-1}\left(\frac{\mathrm{d}}{\ell}\right)
$$

\section{Determination of Hairs Diameter}

Figure 4 shows the top view of cross-sectional SEM image of 4 pairs of hair with each pair was cut by a knife at the same time. It can be clearly observed that the cross-sectional shape of the hairs is nearlay round to slightly oval. These results are in good agreement with those as reported by Robbins (2012). Therefore, from a cross-sectional SEM image in Fig. 5(a), the diameter was measured along 4 different directions as shown in Fig. 5(b) and an average diameter was determined.

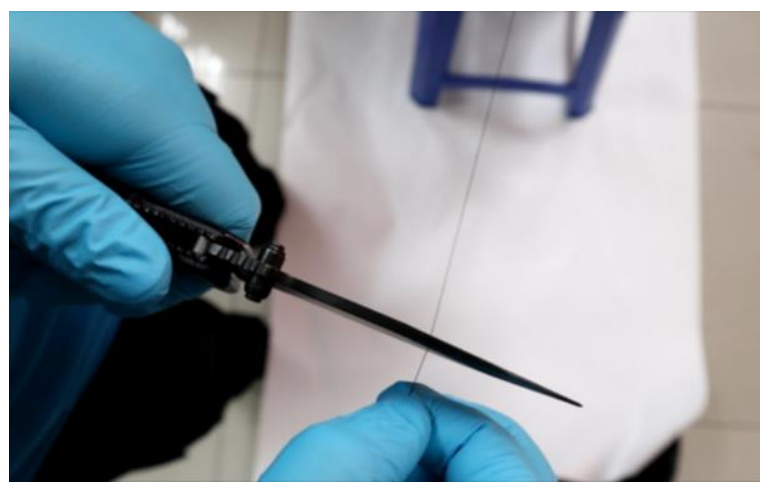

Fig. 1: Showing the cutting of two hairs

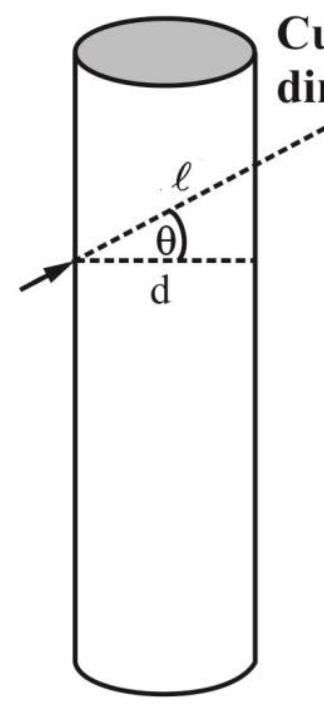

(a)

\section{Cutting direction}

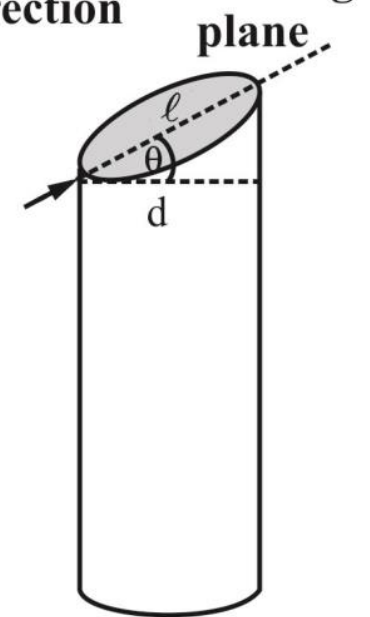

(b)
Fig. 2: Ideal cutting

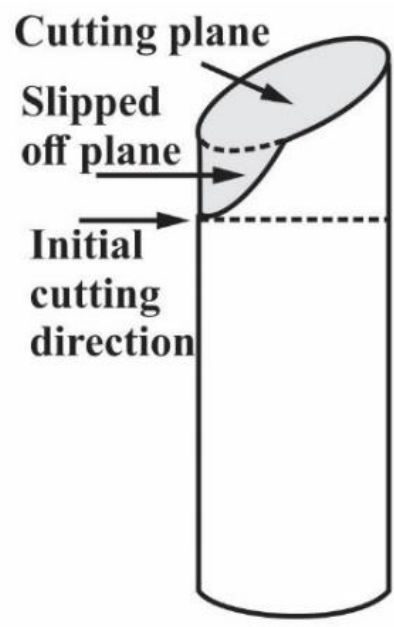

(a)

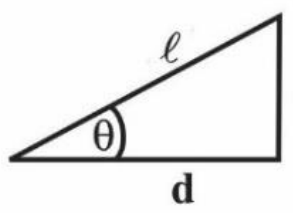

(b)
Fig. 3: Real cutting
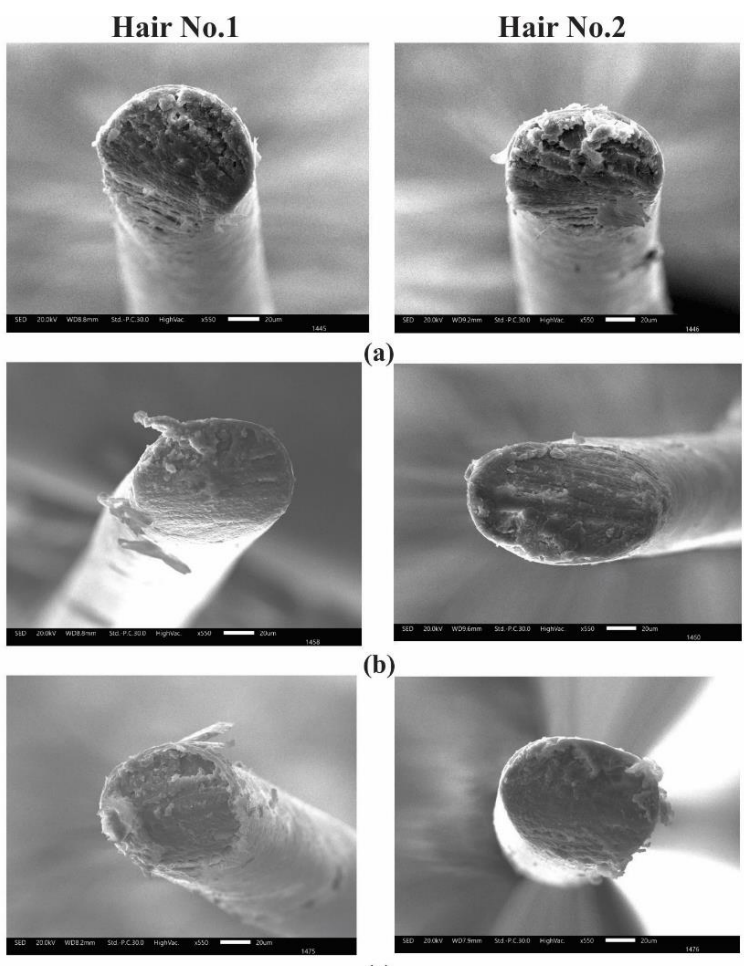

(b)
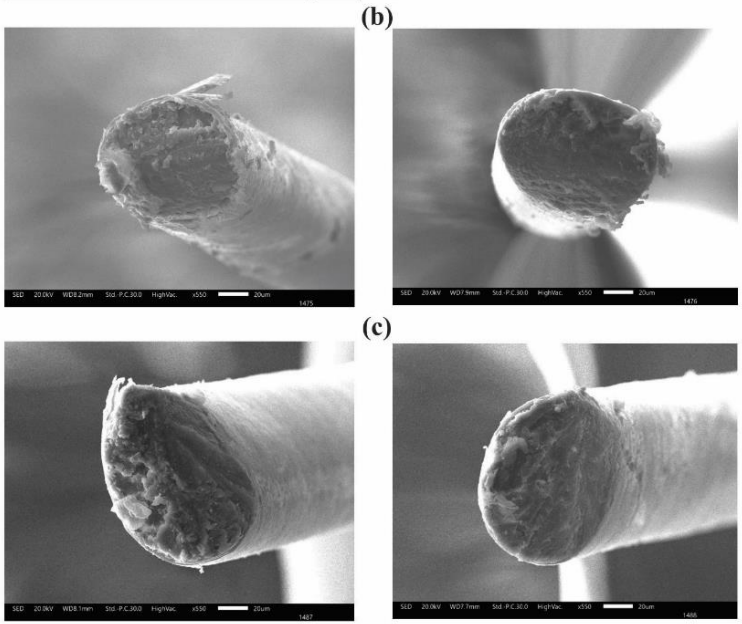

(c)

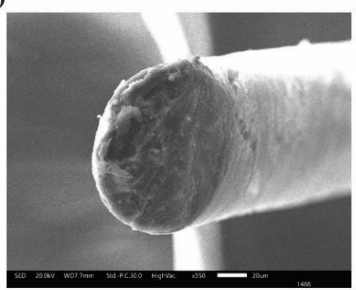

(d)

Fig. 4: Showing the top view of cross-sectional SEM image of (a) $1^{\text {st }}$ pair, (b) $2^{\text {nd }}$ pair, (c) $3^{\text {rd }}$ pair and (d) $4^{\text {th }}$ pair of cut hairs 

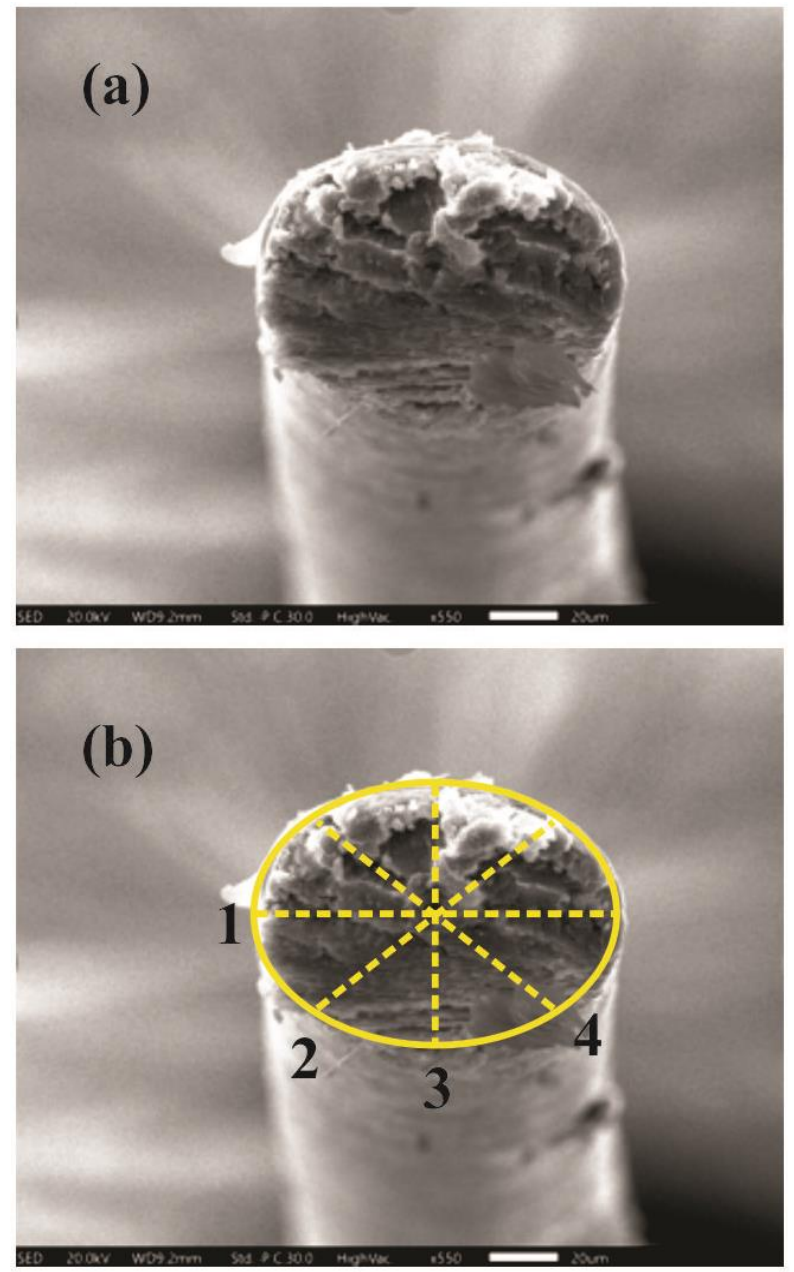

Fig. 5: (a) Showing the cross-sectional SEM image of a hair and (b) the diameter was measured along 4 directions

\section{Results and Discussion}

\section{Results on the Measurement of Hairs Diameter}

The average diameters of 4 pairs of hairs as measured in according with Fig. 5(b) are shown in Table 1. It is seen that the average diameters of 4 pairs of hairs used in this study are ranged from 90.93 to $108.92 \mu \mathrm{M}$. The results obtained are compatible with the hairs of Asian people, such as the work of Nagase et al. (2008) who measured maximum and minimum hair diameters from 132 Japanese females ranging from 10 to 70 years of age. For 8,926 hairs, they found that the average maximum and minimum diameters were $95.3 \pm 16.5$ and $74.4 \pm 10.5 \mu \mathrm{m}$, respectively.

\section{Surface Morphology of Two Hairs as Cut at the Same Time}

To analyze the surface morphology of the cut hairs, the top view of cross-sectional SEM image of the $1^{\text {st }}$ pair of the hairs as shown in Fig. 6 was used for the investigation. Hair consists of three layers: An outer cuticle, a cortex and an inner medulla. From Fig. 6, the cuticle region is about $2 \mu \mathrm{m}$. The cortex region, as shown by the dark area in the upper part of the SEM image, shows circular structure of size about $50 \mu \mathrm{m}$. In this case, an inner medulla cannot be observed due to the overlap of cortex on the medulla area. The lower part of the SEM image still looks like an outer part of the cuticle. Since the hair strand has an elastic characteris, the hair strand may stretch 20-30\% of its length (Velasco et al., 2009). Bhushan (2008) reported that Asian hair has an elastic modulus of $7.5 \pm 0.8 \mathrm{GPa}$. Due to this elasticity, at the beginning of hair cutting, the cuticle was dragged to some depth and then the blade can suddenly cut through the hair as shown by the dark area of the SEM image. Furthermore, the surface morphology as observed from the top view of cross-sectional SEM image of hair no.1 and hair no. 2 that was cut at the same time have very similar characteristics.

\section{Results on the Cutting of Two Hairs at the Same Time}

Figure 7 shows the side-view SEM images of 4 pairs of hairs that were cut for observing and measuring the cutting angle. Since, practically it is not possible to obtain the image with exactly the same feature and same magnification. To measure and obtain the cutting angle with accurate values, we have to put a reference frame corresponding with the alignment direction of the SEM image. Then, the length $(l)$ and diameter (d) were measured using the dimension of bar in each image. The obtained cutting angles for 4 pairs of cut hairs are given in Table 2 .

From Table 2, it is seen that each pair of the hairs that were cut at the same time are almost equal. The results are in good agreement for all 4 pairs. The obtained results could be concluded that each pair of cut hairs were cut at the same time. It should be pointed out that the cutting angles of pairs no. 1 and no. 3 and pairs no. 2 and no. 4 are nearly equal, the surface morphology of these two pairs of cut hairs are quite different (Fig. 7). Hence, to identify that the cut hairs were cut at the same time, the cutting angle and the surface morphology of top view and side view SEM images must be carefully considered.

Table 1: Average diameters of 4 pairs of hairs

\begin{tabular}{lcc}
\hline Pair No. & $d_{\text {hair } 1}(\mu \mathrm{m})$ & $d_{\text {hair } 2}(\mu \mathrm{m})$ \\
\hline 1 & 95.32 & 93.54 \\
2 & 96.58 & 107.80 \\
3 & 90.93 & 95.86 \\
4 & 108.92 & 105.67 \\
\hline
\end{tabular}


Table 2: Cutting angles of 4 pairs of hairs

\begin{tabular}{lcc}
\hline Pair No. & $\theta_{\text {hair } 1}\left({ }^{\circ}\right)$ & $\theta_{\text {hair } 2}\left({ }^{\circ}\right)$ \\
\hline 1 & 14.13 & 12.68 \\
2 & 3.35 & 5.70 \\
3 & 15.65 & 15.36 \\
4 & 3.25 & 2.37 \\
\hline
\end{tabular}

Table 3: Cutting angles of 5 hairs as cut at the same time.

\begin{tabular}{ll}
\hline Hair No. & $\theta\left(^{\circ}\right)$ \\
\hline 1 & 31.91 \\
2 & 32.20 \\
3 & 32.33 \\
4 & 32.55 \\
5 & 32.21 \\
\hline
\end{tabular}
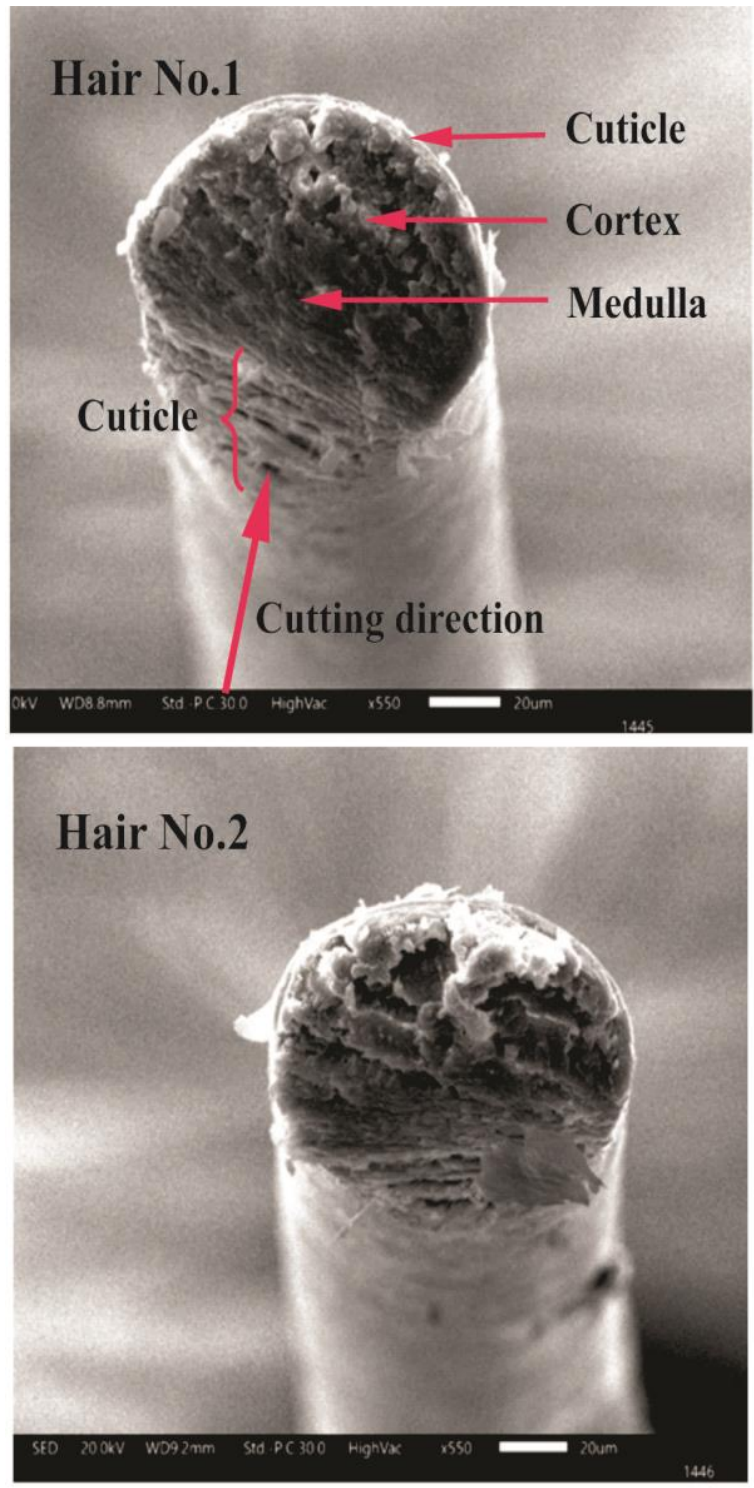

Fig. 6: Showing the top view of cross-sectional SEM image of the 1st pair of cut hairs
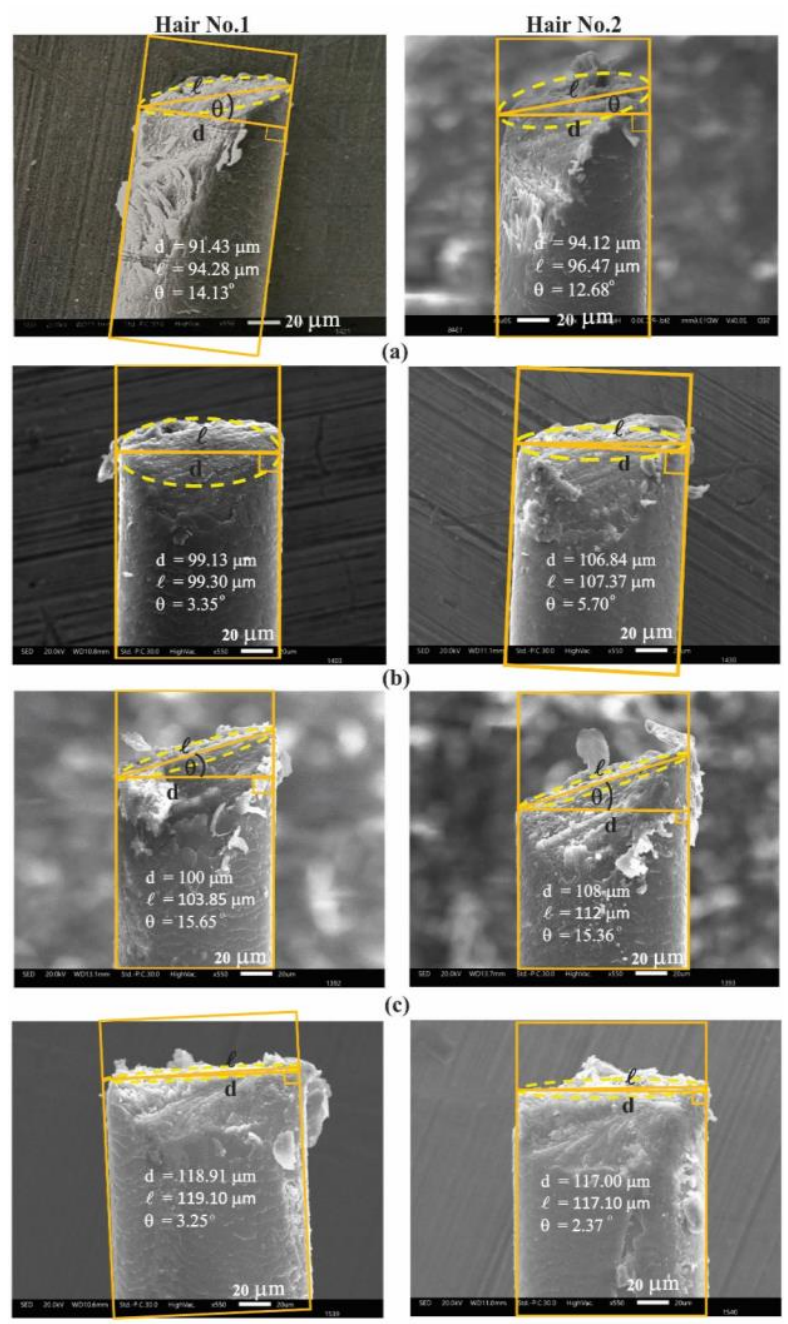

(d)

Fig. 7: Showing the determination of cutting angle of: (a) $1^{\text {st }}$ pair, (b) $2^{\text {nd }}$ pair, (c) $3^{\text {rd }}$ pair and (d) $4^{\text {th }}$ pair of cut hairs

\section{Results on the Cutting of Five Hairs at the Same time}

If more than two hair strands such as five hair strands were cut at the same time, the question is that: Is it possible to declare that they were cut at the same time? Fig. 8 shows the side-view SEM images of 5 hairs that were cut at the same time. The cutting angles as obtained from Fig. 8 for 5 cut hairs are given in Table 3 .

It is interesting that the cutting angles of all 5 hairs are almost equal. This result confirms that if one cut hair strand was found at the suspect's ware and matched by the cutting angle and surface morphology of top view and side view of SEM images with a group of cut hair strands found at the crime scene, it could be concluded that those cut hair stands were cut at the same time. 

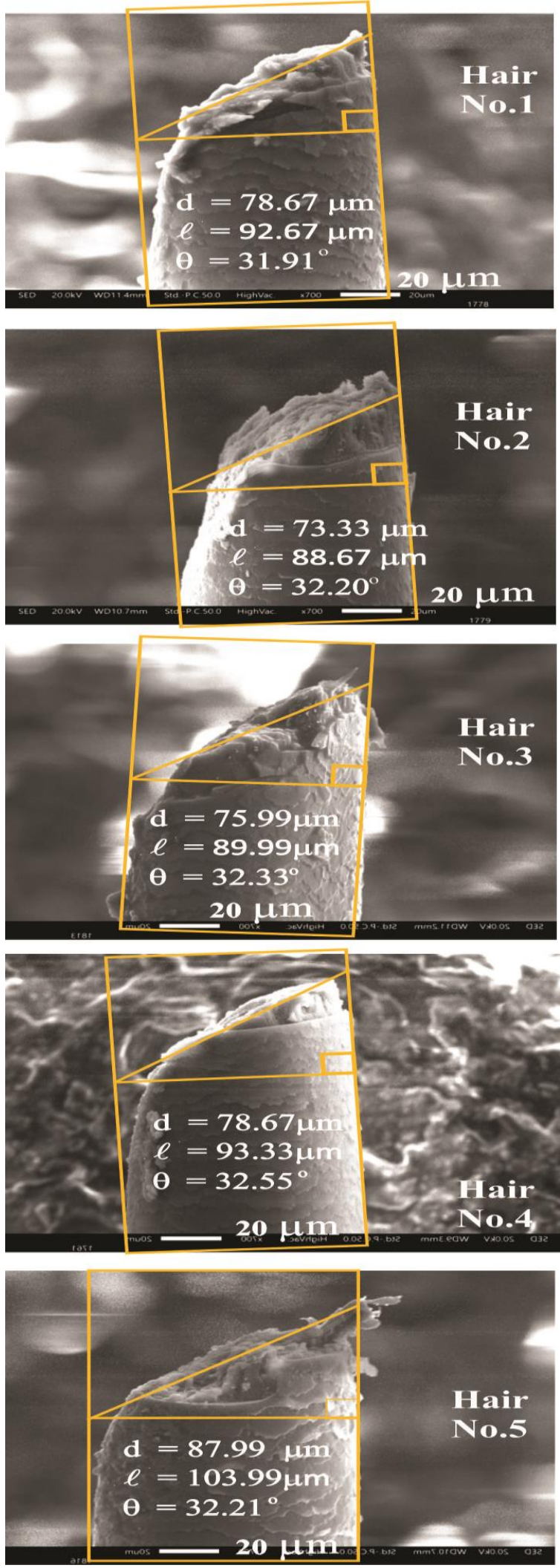

Fig. 8: Showing the side view of cross-sectional SEM image of 5 hairs as cut at the same time

\section{Conclusion}

The cut hair samples, one of the most important evidence of the crime scene have not yet been reported in the literatures. This study reported for the first time on the possibility of matching the cut hairs found at the crime scene with those found at the suspect's ware. Two hair stands and five hair strands were cut at the same time. Then, the size, cutting angle, angular-cut appearance and surface morphology were investigated using scanning electron microscopy. The results obtained from this study show that the cut hairs could be matched and identified as they were cut at the same time.

\section{Acknowledgment}

Pol. Maj. Satina Polyiam, Pol. Lt. Sasithorn Boonmapa would like to thank The Central Scientific Crime Detection Division, Royal Thai Police for financial supporting and providing all facilities to make this study complete.

\section{Funding}

This study was fund by The Central Scientific Crime Detection Division, Royal Thai Police.

\section{Author's and Contributions}

Pol. Maj. Satina Polyiam: Prepared all the equipments used in the experimental setup and carried out the experiment.

Pol. Lt. Sasithorn Boonmapa: Setup and carried out the experiment, collected all the measurement data.

Wuttichai Phae-Ngam: Prepared the obtained results in the form of tables and figures.

Pichet Limsuwan: Prepared the original manuscript.

\section{Compliance with Ethical Standards}

This article is original and contains unpublished material. It is confirmed that all manuscript and there are no ethical issues involved.

\section{Ethical Approval}

This article does not contain any work with human participants or animals. The hair strands used in this study were cut from one author of this study, therefore it is a self-administration study.

\section{Reference}

Allibe, N., Kintz, P., Faure, A., Paysant, F., Michard-Lenoir, A. P., Stanke-Labesque, F., ... \& Eysseric-Guerin, H. (2017). Interest of single hair analysis to document drug exposure: Literature review and a case report involving zuclopenthixol. Current Pharmaceutical Design, 23(36), 5502-5510.

doi.org/10.1016/j.forsciint.2015.01.012 
Baumgartner, A. M., Jones, P. F., Baumgartner, W. A., \& Black, C. T. (1979). Radioimmunoassay of hair for determining opiate-abuse histories. Journal of Nuclear Medicine: Official Publication, Society of Nuclear Medicine, 20(7), 748-752.

https://europepmc.org/article/med/541713

Baumgartner, W. A., Black, C. T., Jones, P. F., \& Blahd, W. H. (1982). Radioimmunoassay of cocaine in hair: Concise communication. Journal of Nuclear Medicine, 23(9),790-792.

https://jnm.snmjournals.org/content/jnumed/23/9/790 .full-text.pdf

Bhushan, B. 2008. Nanoscale characterization of human hair and hair conditioners. Progress in Materials Science 53, 585-710. doi.org/10.1016/j.pmatsci.2008.01.001

Dorea, J. G., Merchan-Hamann, E., Ryan, D. E., \& Holzbecher, J. (1989). Retention of antimony in hair during leishmaniasis treatment. Clinica chimica acta, 179(3), 341-345. doi.org/10.1016/0009-8981(89)90097-1

Duvivier, W. F., van Beek, T. A., Pennings, E. J., \& Nielen, M. W. (2014). Rapid analysis of $\Delta$-9tetrahydrocannabinol in hair using direct analysis in real time ambient ionization orbitrap mass spectrometry. Rapid Communications in Mass Spectrometry, 28(7), 682-690. doi.org/10.1002/rcm.6831

Flinders, B., Cuypers, E., Zeijlemaker, H., Tytgat, J., \& Heeren, R. M. (2015). Preparation of longitudinal sections of hair samples for the analysis of cocaine by MALDI-MS/MS and TOF-SIMS imaging. Drug Testing and Analysis, 7(10), 859-865. doi.org/10.1002/dta.1812

Graham, K., Koren, G., Klein, J., Schneiderman, J., \& Greenwald, M. (1989). Determination of gestational cocaine exposure by hair analysis. JAMA, 262(23), 3328-3330. doi.org/0.1001/jama.1989.03430230113036

Ishiyama, I., Nagai, T., \& Toshida, S. (1983). Detection of basic drugs (methamphetamine, antidepressants and nicotine) from human hair. Journal of Forensic Science, 28(2), 380-385. astm.org/DIGITAL_LIBRARY/JOURNALS/FOR ENSIC/PAGES/JFS11518J.htm

Kelly, R. C., Mieczkowski, T., Sweeney, S. A., \& Bourland, J. A. (2000). Hair analysis for drugs of abuse: Hair color and race differentials or systematic differences in drug preferences? Forensic Science International, 107(1-3), 63-86. doi.org/10.1016/s0379-0738(99)00151-6

Khajuria, H., Nayak, B. P., \& Badiye, A. (2018). Toxicological hair analysis: Pre-analytical, analytical and interpretive aspects. Medicine, Science and the Law, 58(3), 137-146. doi.org/10.1177/0025802418768305
Kintz, P., \& Mangin, P. (1993). Opiate concentrations in human head, axillary and public hair. Journal of Forensic Science, 38(3), 657-662. doi.org/10.1520/JFS13452J

Kuwayama, K., Miyaguchi, H., Iwata, Y. T., Kanamori, T., Tsujikawa, K., Yamamuro, T., ... \& Inoue, H. (2016). Three-step drug extraction from a single submillimeter segment of hair and nail to determine the exact day of drug intake. Analytica Chimica acta, 948, 40-47. doi.org/10.1016/j.aca.2016.10.029

Marigo, M., Tagliaro, F., Poiesi, C., Lafisca, S., \& Neri, C. (1986). Determination of morphine in the hair of heroin addicts by high performance liquid chromatography with fluorimetric detection. Journal of Analytical Toxicology, 10(4), 158-161. doi.org/10.1093/jat/10.4.158

Marques, P. R., Tippetts, A. S., \& Branch, D. G. (1993). Cocaine in the hair of mother-infant pairs: Quantitative analysis and correlations with urine measures and self-report. The American Journal of Drug and Alcohol Abuse, 19(2), 159-175. doi.org/10.3109/00952999309002677

Miki, A., Keller, T., Regenscheit, P., Dirnhofer, R., Tatsuno, M., Katagi, M., ... \& Tsuchihashi, H. (1997). Application of ion mobility spectrometry to the rapid screening of methamphetamine incorporated in hair. Journal of Chromatography B: Biomedical Sciences and Applications, 692(2), 319-328. doi.org/10.1016/S0378-4347(96)00530-0

Nagai, T., \& Kamiyama, S. (1988). Forensic toxicologic analysis of methamphetamine and amphetamine optical isomers by high performance liquid chromatography. Zeitschrift für Rechtsmedizin, 101(3), 151-159. doi.org/10.1007/bf00201110

Nagase, S., Tsuchiya, M., Matsui, T., Shibuichi, S., Tsujimura, H., Masukawa, Y., Satoh, N., Itou, T., Koike, K., \& Tsujii, K. (2008). Characterization of curved hair of Japanese women with reference to internal structures and amino acid composition. Journal of cosmetic science, 59, 317-332.

https://europepmc.org/article/med/18818851

Nakanishi, T., Nirasawa, T., \& Takubo, T. (2014). Quantitative mass barcode-like image of nicotine in single longitudinally sliced hair sections from long-term smokers by matrix-assisted laser desorption time-offlight mass spectrometry imaging. Journal of Analytical Toxicology, 38(6), 349-353. doi.org/10.1093/jat/bku032

Offidani, C., Rossi, S. S., \& Chiarotti, M. (1993). Drug distribution in the head, axillary and pubic hair of chronic addicts. Forensic Science International, 63(1-3), 105-108. doi.org/10.1016/0379-0738(93)90264-b

Porta, T., Grivet, C., Kraemer, T., Varesio, E., \& Hopfgartner, G. (2011). Single hair cocaine consumption monitoring by mass spectrometric imaging. Analytical Chemistry, 83(11), 4266-4272. doi.org/10.1021/ac200610c 
Püschel, K., Thomasch, P., \& Arnold, W. (1983). Opiate levels in hair. Forensic Science International, 21(2), 181-186. doi.org/10.1016/0379-0738(83)90108-1

Robbins, C.R. 2012. Chemical and Physical Behavior of Human, H., $5^{\text {th }}$ Edition, Springer-Verlag Berlin, Heidelberg. 2012. ISBN 978-3-642-25610-3 e-ISBN 978-3-642-25611-0. doi.org/10.1007/978-3-642-25611-0

Robertson, J. 1999. editor, Forensic Examination of Hair, Taylor \& Francis, Philadelphia, ISBN-101: 0-203-48352-9.

Stewart-Pinkham, S. M. (1989). The effect of ambient cadmium air pollution on the hair mineral content of children. Science of the Total Environment, 78, 289-296. doi.org/10.1016/0048-9697(89)90039-9

Suzuki, O., Hattori, H., \& Asano, M. (1984). Detection of methamphetamine and amphetamine in a single human hair by gas chromatography/chemical ionization mass spectrometry. Journal of Forensic Science, 29(2), 611-617. doi.org/10.1520/JFS11712J
Thozhur, S. M., Crocombe, A. D., Smith, P. A., Cowley, K., \& Mullier, N. (2006). Structural characteristics and mechanical behaviour of beard hair. Journal of Materials Science, 41(4), 1109-1121. doi.org/10.1007/s10853-005-3648-2

Usman, M., Naseer, A., Baig, Y., Jamshaid, T., Shahwar, M., \& Khurshuid, S. (2019). Forensic toxicological analysis of hair: A review. Egyptian Journal of Forensic Sciences, 9(1), 1-12. doi.org/10.1186/s41935-019-0119-5

Velasco, M. V. R., de Sá Dias1, T. C., de Freitas, A. Z., Vieira Jr, N. D., de Oliveira Pinto, C. A. S., Kaneko, T. M., Baby, A. R. (2009). Hair fiber characteristics and methods to evaluate hair physical and mechanical properties, Brazilian. Journal of Pharmaceutical Sciences, 45, 1, 153-166. https://pdfcookie.com/documents/hair-fibercharacteristics-and-methods-to-evaluate-hairphysical-and-mechanical-properties-90258y44o421 